\title{
EphB1 controls proper long-range cortical axon guidance through a cell non-autonomous role in GABAergic cells
}

\author{
Ahlem Assali ${ }^{1,}$, , George Chenaux ${ }^{2,3}$, Christopher W. Cowan ${ }^{1,2,}{ }^{*}$ \\ ${ }^{1}$ Department of Neuroscience, Medical University of South Carolina, Charleston, SC \\ ${ }^{2}$ Department of Psychiatry, University of Texas Southwestern Medical School, Dallas, TX \\ ${ }^{3}$ Current address: Bio-Rad Laboratories, Inc., Hercules, California. \\ *Co-corresponding authors: ahlem_assali@yahoo.fr and cowanc@musc.edu
}

Key words:

axon guidance, EphB1, GABAergic long-range projections, cerebral vasculature.

\begin{abstract}
EphB1 is required for proper guidance of cortical long-range axon projections during brain development, but how EphB1 regulates this process remains unclear. To determine the relevant cell types in which EphB1 functions for proper cortical axon guidance, we generated a new floxed EphB1 mouse. We show here that EphB1 conditional knockout (cKO) in most of the developing cortical excitatory neurons (Emx1-Cre) failed to produce cortical axon guidance defects. However, EphB1 cKO in GABAergic cell populations (Vgat-Cre or dlx1/2-Cre) reproduced fully the cortical axon guidance defects observed in global $E p h B 1^{-/-}$mice. Interestingly, in the $E p h B 1 \mathrm{cKO}^{\mathrm{Vgat}}$ mice, the misguided axon bundles in the dorsal striatum contained comingled striatal GABAergic and cortical glutamatergic axons. Surprisingly, conditional loss of EphB1 in D1 or D2 dopamine receptor-expressing populations did not produce the cortical axon guidance defects, and no D1- or D2-SPN axons were detected within the misguided axon bundles of EphB1 KO mice. In contrast, parvalbumin-positive GABAergic cell axons were observed in the misguided axon bundles in EphB1 KO mice. Finally, a large fraction of the ectopic axons in EphB1 KO mice were in close apposition to the major blood vessels in the ventral telencephalon, suggesting that EphB1 expression in GABAergic cells normally promotes avoidance of these ectopic long-range axons from the developing cerebral vasculature. Together, our data reveal a new role for EphB1 in GABAergic cells to influence proper cortical glutamatergic long-range axon guidance during early brain development.
\end{abstract}




\section{INTRODUCTION}

In the developing nervous system, binding of EphB tyrosine kinase receptors to their cell surface-localized ephrin "ligands" triggers bidirectional, intracellular signaling events that regulate proper axon guidance, cell migration, synapse formation and plasticity [1]. Previous studies revealed deep-layer cortical axon guidance defects in the ventral telencephalon (VTel) of EphB1- mice [2-4], and these guidance errors were exacerbated in the EphB1 $1^{--} ; E p h B 2^{-/-}$mice, suggesting partial compensation by EphB2 receptors [2]. EphB1 shows peak expression in cortical layers $\mathrm{V}$ and VI at mouse embryonic day 15.5 (E15.5) [2,4] - a time when long-range cortical axons are navigating toward their subcortical target zones [5]. However, at this developmental stage, EphB1 is also expressed in the developing epithalamus [2], GABAergic cell progenitor structures (i.e., ganglionic eminences and the preoptic area), GABAergic interneurons migrating toward the developing cortex [6], and GABAergic spiny projection neurons (SPNs) of the developing striatum. Developing deep-layer cortical axons also express ephrin-Bs and navigate through EphB1-expressing brain regions in the VTel. As such, it was unclear whether EphB1 regulates cortical axon guidance in a cortical cell autonomous manner or whether EphB1 regulates longrange cortical glutamatergic projections indirectly via a key role in other cell populations.

To investigate the cell populations in which EphB1 regulates proper cortical axon guidance, we generated a new floxed EphB1 mouse to allow for Cre-dependent EphB1 loss-offunction analysis. Our findings reveal that EphB1 is required within Vgat (vesicular GABA transporter)-positive cells, but surprisingly, not in excitatory cortical neurons, to control longrange cortical axon guidance in the VTel. Moreover, in EphB1 KO mice, we observed numerous aberrant subcortical axon bundles comprising both GABAergic striatal axons and glutamatergic cortical axons that preferentially grew along major blood vessels in the VTel, but these effects were not produced by EphB1 loss-of-function in either D1 or D2 dopamine receptor-expressing SPNs or Tie2-expressing vascular endothelial cell populations, suggesting that EphB1 functions in Vgat-positive cells to indirectly produce cortical axon guidance defects in apposition to developing striatal vasculature.

\section{MATERIAL AND METHODS}

Animals. EphB1 knockout mice (EphB1 ${ }^{-/}$) on a C57BL/6 background were generated by crossing $E p h B 1^{-/-}$mice on a CD-1 background (donated by Dr. Henkemeyer, [7]) to C57BL/6 background strain (>8 generations). EphB1-LacZ mice were donated by Dr. Henkemeyer [8]. EphB1 $1^{\triangle \mathrm{E} \times 3 / \Delta \mathrm{Ex} 3}$ mice ( $E p h B 1$ total loss-of-function) were generated by crossing floxed $E p h B 1$ mice (EphB1 ${ }^{\text {lox/lox }}$, described below) to Prm-Cre mice (Jackson Laboratory \#003328) to produce germline recombination. The Prm-Cre allele was subsequently removed during repeated backcrossing to C57BL/6J wild-type mice. $E p h B 1$ conditional knockout mice $(E p h B 1 \mathrm{cKO})$ were generated by crossing $E p h B 1^{\text {lox/lox }}$ mice with cell type-selective Cre-expressing transgenic mice (Emx1-Cre 
(Jackson Laboratory \#005628), Vgat-Cre (Jackson Laboratory \#028862), dlx1/2-Cre (I12b-Cre donated by Dr. Rubenstein, Potter et al, 2009), Somatostatin-Cre (Sst-Cre, Jackson Laboratory \#013044), Drd1a-Cre (Jackson Laboratory \#37156-JAX), Drd2-Cre (GENSAT; MMRRC \# 036716-UCD), Tie2-Cre (Jackson Laboratory \# 008863), parvalbumin-Cre (PV-Cre, Jackson Laboratory \# 017320), and they were compared to their Cre-negative littermate controls. The Vgat-Cre, Tie2-Cre and PV-Cre lines were crossed to the Ai14 reporter mouse line (Jackson Laboratory \#007914). To visualize long-range GABAergic projections, the Vgat-Cre line was crossed to both EphBl lox/lox and Ai14 (EphB1 $\mathrm{cKO}^{\text {Vgat; }}$ tdTomato ${ }^{\text {Vgat }}$ ) mice or to Ai14 (tdTomato $^{\text {Vgat }}$ ). To visualize thalamic and striatal axons in EphB1 mice, Gbx-CreER ${ }^{\mathrm{T} 2}$-IRES-EGFP (Jackson Laboratory \#022135), D1-tdTomato (Jackson Laboratory \#016204) and D2-GFP (Mouse Genome Informatics MGI:3843608) reporter mice were crossed to EphB1-- mice or to $E p h B 1^{\Delta \mathrm{Ex} 3 / \Delta \mathrm{Ex} 3}$ mice. To visualize the projections from parvalbumin positive neurons, the PVtdTomato reporter line (Jackson Laboratory, \#027395) was crossed to EphB1 $1^{\Delta \mathrm{Ex} 3 / \Delta \mathrm{Ex} 3}$ mice. All procedures were conducted in accordance with the MUSC Institutional Animal Care and Use Committee (IACUC) and NIH guidelines.

Generation of floxed EphB1 mutant mice (EphB ${ }^{\text {loxllox}}$; Suppl. Figure 1). A targeting vector was generated by using a pL452 based mini targeting vector [9], which was recombineered into mouse 129 strain bacterial artificial chromosome clone BMQ422J21 [10]. The mini targeting vector was cloned so that loxP site \#1 was inserted 722 bp upstream of EphB1 exon 3 and loxP site \#2 is 293 bp downstream of exon 3. In addition to this, an FRT site flanked insertion was cloned downstream of loxP site \#1, which contained the following cassettes: an engrailed 2 slice acceptor, the internal ribosomal entry site (IRES) from encephalomyocarditis virus (EMCV) [11], a bovine tau protein \& enhanced green fluorescent protein (eGFP) expression sequence [12], an SV40 polyadenylation signal, and a neomycin selection cassette driven by prokaryotic and eukaryotic constitutive promoters. A capture vector as used to retrieve 10,630 bp for the left homology arm and 10,146 bp is for the right homology arm with flanking diphtheria toxin and thymidine kinase negative selection cassettes, respectively. Murine stem cells were targeted and screened by the UC Davis Mouse Biology Program. Mice were crossed with a Flp recombinase germline expression mice to remove the FRT flanked knock-in cassettes to generate $E p h B 1^{\text {lox/lox }}$ mice lacking the selection cassettes. Cells that express Cre recombinase delete $1854 \mathrm{bp}$ of the EphBl genomic locus, which includes all of exon 3, to generate EphB $1^{\Delta \text { exon3 }}$ mice. Exons 1 and 2 have the potential to generate a small, truncated protein. In the $E p h B 1^{\Delta \text { exon3 }}$ mice, exon 2 splicing to exon 4 is predicted to produce either nonsense mediated decay or to code for the following protein sequence: MALDCLLLFLLASAVAAMEETLMDTRTATAELGWTANPASGPVLRGPSRPARKLKAA PTAPPTVAPLQRRLPSAPAGLAITELTLIHQRWRVLVSHRVLEMSSPS, Bolded letters are produced by a frame-shift and represent the predicted non-EphB1 amino acids prior to the premature stop codon. The primers used to genotype floxed EphB1 mice were: forward primer 5'GGGAGAAGAGAGAGCCTAC3', and reverse primer 5'CCAGAGGGCTTTGAGTTAAT3' (floxed band: 316bp; wild-type band: 420bp), using a PCR mix and a PCR program detailed in Suppl. Figure 2. 
Immunohistochemistry. Adult mice were anesthetized with Ketamine/Xylazine diluted in 0.9\% saline $(120 \mathrm{mg} / \mathrm{kg}$ and $16 \mathrm{mg} / \mathrm{kg}$, respectively) and hypothermia anesthesia was used for pups by placing them in ice for 5-8 minutes. Postnatal day 0 (P0) pups and adult mice were perfused transcardially with $4 \%(\mathrm{w} / \mathrm{v})$ paraformaldehyde (PFA) in phosphate buffered saline (PBS), the brains were post-fixed overnight in $4 \%$ PFA, cryoprotected in 30\% sucrose, and then sectioned at $40 \mu \mathrm{m}$ (adults) and $70 \mu \mathrm{m}$ (pups) using a cryotome. Sections were washed in PBS, incubated in blocking solution (5\% (v/v) normal donkey serum, $1 \%$ (w/v) Bovine Serum Albumin, 0.2\% (v/v) glycine, $0.2 \%(\mathrm{w} / \mathrm{v})$ lysine, $0.3 \%(\mathrm{v} / \mathrm{v})$ Triton X-100 in PBS) for 1 hour at room temperature (RT) with shaking, incubated with primary antibodies diluted in blocking solution (rat anti-L1CAM (1:1000) from MilliporeSigma \#MAB5272; chicken anti-GFP (1:1000) from Abcam \#13970; mouse anti-Brn3a (1:200) from Fisher \#MAB1585; rabbit anti-DsRed (1:1000) from Living Colors \#632496; goat anti-CD31 (1:800) from Novus Biologicals \#AF3628; mouse anti-elastin (1:800) from Sigma \#MAB2503) overnight at 4C under shaking, washed 3 times for 10 minutes in PBS with gentle shaking at RT, incubated with secondary antibodies diluted in blocking solution (Cy3 donkey anti-rat (1:500) from Fisher \#NC0236073; AlexaFluor 488 donkey anti-mouse (1:500) from Fisher \#NC0192065; AlexaFluor 488 donkey anti-chicken (1:500) from Fisher \#703545-155) for 90 minutes at RT with shaking and protected from light, washed 3 times for 10 minutes in PBS, and mounted in ProLong Gold Antifade Mountant (Invitrogen \#P36931).

XGal staining. Adult mice were perfused transcardially with $4 \%(\mathrm{w} / \mathrm{v}) \mathrm{PFA}$, and the brains were post-fixed overnight in $4 \%(\mathrm{w} / \mathrm{v})$ PFA. Female mice were bred and vaginal plugs were assessed with the day of plug detection considered as embryonic day 0.5 (E0.5). After live-decapitation, embryo brains were drop-fixed in 4\% PFA overnight. Adult and embryo brains were then cryoprotected in $30 \%$ sucrose. Embryo brains were plunged in M1-embedding matrix (ThermoFisher \#1310), flash-frozen for 1 minute in isopentane between $-20^{\circ} \mathrm{C}$ and $-30^{\circ} \mathrm{C}$, and stored at $-80^{\circ} \mathrm{C}$. Adult brains were cut at $40 \mu \mathrm{m}$ using a cryotome and embryo brains at $20 \mu \mathrm{m}$ using a cryostat. XGal staining was performed using the beta-galactosidase staining kit (Mirus \#MIR 2600), following the provided protocol. Briefly, the sections were washed in PBS, incubated in the Cell Staining Working Solution containing the X-Gal Reagent in a dark, humidified chamber at $37^{\circ} \mathrm{C}$ overnight, washed once in PBS, and mounted in ProLong Gold Antifade Mountant (Invitrogen \#P36931).

Myelin Stain. Sections were stained for myelin using the BrainStain Imaging kit (ThermoFisher \#B34650; FluoroMyelin, 1:300), following the vendor protocol.

$\boldsymbol{R} \boldsymbol{T}-\boldsymbol{P C} \boldsymbol{R}$. RNA extraction was performed using the miRNeasy Mini kit (Qiagen \#1038703), following the kit's protocol. Total RNA was reverse-transcribed using Superscript III (Invitrogen) with random hexamers, following the kit's protocol. PCRs were performed using the complementary DNA to detect EphBl expression (for EphBl $\mathrm{cKO}^{\text {Emx: }}$ forward primer 5' TACAGAGATGCGCTT 3', reverse primer 5' ACAGCGTGGCCTGCA 3'; for EphB1 $1^{\Delta E x 3 / \Delta E x 3}$ and for $E p h B 1 \mathrm{cKO}^{\mathrm{vgat}}$ : forward primer 5' AGACATTGATGGACACAAGG 3', reverse primer 5' TCAAAGTCAGCTCGGTAATA 3'). GAPDH was used as a control (forward primer 5' 


\section{TGAAGGTCGGTGTCAACGGATTTGGC}

$3^{\prime} ;$

'; $\quad$ reverse $\quad$ primer

5 ,

CATGTAGGCCATGAGGTCCACCAC 3').

$\boldsymbol{R N A s c o p e}^{\circledast}$. After live-decapitation, the brains were plunged in M1-embedding matrix (ThermoFisher \#1310), flash-frozen for 1 minute in isopentane between $-20^{\circ} \mathrm{C}$ and $-30^{\circ} \mathrm{C}$, stored at $-80^{\circ} \mathrm{C}$, and then cut at $16 \mu \mathrm{m}$ thick slices using a cryostat. Sections were kept at $-20^{\circ} \mathrm{C}$ during all the cutting process and stored at $-80^{\circ} \mathrm{C}$. RNAscope ${ }^{\circledR}$ was performed using the RNAscope ${ }^{\circledR}$ kit (ACD \#323110) and following the ACD protocol provided by the manufacturer. Sections were immersed in 4\% (w/v) PFA for 15 minutes, then in 50\% (v/v) EtOH for 5 minutes, then in $70 \%$ (v/v) EtOH for 5 minutes, and then twice in $100 \% \mathrm{EtOH}$ for 5 minutes. Sections were covered by RNAscope ${ }^{\circledR}$ Hydrogen Peroxide for 10 minutes in a humidified chamber and washed 3 times in PBS, and the protease incubation step was omitted. Sections were placed in a humidified chamber in the HybEZ ${ }^{\mathrm{TM}}$ Oven for all the following steps at $40^{\circ} \mathrm{C}$ and were washed twice for 2 minutes in Wash Buffer after each of the following incubation steps. Sections were incubated with the probes (ACD EphB1 custom probe designed in EphB1 exon3 \#541171-C2; Vgat probe \#319191; tdTomato probe \#317041-C3; C1 probes were used without dilution; C2 and C3 probes were diluted 50 times in $\mathrm{C} 1$ probe or in Diluent) and placed at $40^{\circ} \mathrm{C}$ for 2 hours. AMP1, AMP2, and AMP3 were successively applied on the sections for 30 minutes each at $40^{\circ} \mathrm{C}$. Sections were then covered by the appropriate HRP-C and placed at $40^{\circ} \mathrm{C}$ for 15 minutes, covered by the appropriate fluorophore (PerkinElmer \#NEL744E001KT (Cyanine3); \#NEL741E001KT (Fluorescein); \#NEL745E001KT (Cyanine5); 1:2000 in TSA Buffer provided in RNAScope ${ }^{\circledR}$ kit), placed at $40^{\circ} \mathrm{C}$ for 30 minutes, covered by the HRP blocker and incubated at $40^{\circ} \mathrm{C}$ for 15 minutes. Finally, DAPI was applied for 1 minute and sections were mounted in ProLong Gold Mountant (Invitrogen \#P36931).

Stereotaxic injections. Unilateral stereotaxic injections of AAV5-CaMKII $\alpha$-EGFP (Addgene \#50469; virus titer $\geq 3 \times 10^{12} \mathrm{vg} / \mathrm{mL}$ ) and AAV5-hSyn-DIO-hM4D(Gi)-mCherry (Addgene $\# 44362$; virus titer $\geq 7 \times 10^{12} \mathrm{vg} / \mathrm{mL}$ ) viruses were performed on adult anesthetized (isoflurane) control (Vgat-Cre) and EphB1 cKO ${ }^{\text {gat }}$ (EphB1 lox/lox:Vgat-Cre) mice, into the dorsal striatum (DV: -2.8, ML: +1.6, AP: $0 ; 150 \mathrm{~nL})$ and into two locations of the somatosensory cortex (1. DV: -1.9 , ML: +3.2, AP: -0.4 ; 2. DV: -1.4 , ML: +2.7, AP: $-1.7 ; 200 \mathrm{~nL}$ in each location), using a Nanoinjector (FisherScientific \#13-681-455; 50nL/30sec). Placement was confirmed by immunohistochemistry (GFP and DsRed antibodies; see above).

\section{RESULTS}

\section{Cortical axon guidance defects in $\operatorname{EphB1} \mathrm{KO}$ mice}

Since the background strain can influence phenotypes in mutant mice, we backcrossed the EphB1 $1^{-/-}$mice (on a CD-1 background; [7]) to C57BL/6 background strain (>8 generations).

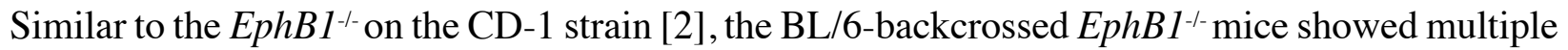
axon guidance defects at postnatal day 0 (P0) (Fig. 1), including disorganized axons and ectopic 
axon bundles within the dorsal striatum (Fig. $1 B$ and $C$; see arrows), descending ectopic axon bundles within the internal capsule, and ectopic axon projections descending from the external capsule and terminating near the brain floor (Fig. $1 B$ and $D$; see arrows). Previous studies also showed that axons from the somatosensory cortex aberrantly grow in the posterior branch of the anterior commissure in EphB1 $1^{-/}$mice [4].

Since misguided VTel axons in EphB1 $1^{-/}$mice originate largely from the cortex [2, 4] and ascending thalamocortical projections are thought to influence corticothalamic axon guidance [13], we analyzed $G b x$-expressing thalamocortical projections in the $E p h B 1^{-/-}$mice. In the $E p h B 1^{-/-}$mice, the Gbx-EGFP-labeled axon projections appeared normal (Suppl. Fig. 3A and $B$ ), the L1CAMpositive misguided axons did not co-localize with GFP-positive thalamic fibers (Suppl. Fig. 3C and $C^{\prime}$ ), and the cortical barrel fields were similar to wild-type controls (Suppl. Fig. $3 D$ and $E$ ), suggesting that the cortical axon guidance errors in the VTel of EphB1 ${ }^{-1-}$ mice are unlikely to be caused by aberrant thalamocortical axon navigation.

EphB1 is highly expressed in a dorsal region of the early developing thalamus [2]. Careful analysis of EphB1 expression (using Xgal staining in EphB1-lacZ mice) in the Gbx-EGFP mice showed that its expression is increased in the epithalamus (Suppl. Fig. 4), but largely undetectable in the developing thalamus (Suppl. Fig. 4A). Indeed, the habenula-specific marker Brn3a [14] revealed strong co-localization with EphB1 (ß-gal) at E14.5, and EphB1 was highly expressed in the adult habenula (Suppl. Fig. $4 B$ and $C$, respectively). Despite its strong expression in habenula, we detected no axon guidance defects in the habenular commissure, the fasciculus retroflexus, or the habenular axon tract in the interpeduncular nucleus in P0 EphB1-1- pups (Suppl. Fig. 4D). Together these findings suggest that EphB1 is expressed highly in the developing epithalamus/habenula, but it's not required for normal habenular (or thalamic) axon guidance.

\section{Generation of an $E$ phB1 conditional loss-of-function mutant mouse}

To determine the cell population(s) in which EphB1 functions to regulate proper cortical axon guidance, we generated a mutant mouse with loxP sites flanking EphB1 exon 3 (Fig. 2A; Suppl. Fig. 1) using traditional homologous recombination. To confirm that Cre-dependent loss of $E p h B 1$ exon 3 reproduced the original $E p h B 1^{-/}$phenotype, we generated germline transmission of the $\Delta$ exon 3 allele (Prm1-Cre). After extensive backcrossing to C57BL/6, we confirmed the loss of $E p h B 1$ expression in the brain of $E p h B 1^{\Delta \mathrm{E} \times 3 / \Delta \mathrm{Ex} 3}$ mice (Fig. $2 B$ ), and importantly, we observed the same VTel axon guidance defects observed in the original EphB1/- mice (Fig. 2D).

\section{EphB1 regulates cortical axon guidance via a role in GABAergic neurons}

Since EphB1 is expressed in the deep layers of the developing cortex [2, 4], we crossed $E p h B 1^{1 \text { lox/lox }}$ mice with Emx 1-Cre mice to generate conditional EphB1 KO $\left(E p h B 1 \mathrm{cKO}^{\mathrm{Emx} 1}\right)$ in most cortical and hippocampal glutamatergic pyramidal neurons starting at $\sim$ E11.5 [15]. Despite the loss of cortical EphB1 expression in the EphB1 cKO ${ }^{\mathrm{Emx} 1}$ mice (Suppl. Fig. 5A), we observed no axon guidance defects (Figs. 3A and 3B). EphB1 is also highly expressed in multiple GABAergic neuron populations $[2,6]$, including those within the developing VTel. To test EphB1 function in 
GABAergic neurons, we generated a $E p h B 1 \mathrm{cKO}$ in virtually all GABAergic populations using Vgat-ires-Cre mice [16] (see Suppl. Figs. 5B, $C$, and D). Interestingly, P0 EphB1 cKO ${ }^{\text {vgat pups }}$ completely phenocopied the cortical axon guidance defects found in the global EphB1 $1^{-/}$pups (see Figs. $3 C$ and $D$ ). We also observed the cortical axon guidance defects in P0 EphB1 $\mathrm{cKO}^{d l x l / 2}$ pups (Fig. 5A) - a distinct GABAergic cell-specific Cre transgenic mouse [17]. Together, these data revealed that EphB1 functions in GABAergic cells to influence cortical axon guidance.

\section{Cortical axons co-fasciculate with misguided striatal GABAergic axons in absence of EphB1}

GABAergic striatal SPNs, and a subset of cortical GABAergic neurons (e.g., some parvalbumin- or somatostain-positive neurons), project long-range to subcortical regions [18]. Using compound mutant mice EphB1 $\mathrm{cKO}^{\text {vgat }}$ tdTomato $^{\text {Vgat }}\left(E p h B 1^{\text {lox/lox }} \mathrm{x}\right.$ Vgat-Cre x Ai14 ), we observed GABAergic axons located within the L1CAM-positive ectopic axon bundles (Figs. $3 E$ and $F$ ), indicating that some GABAergic axons are found within the ectopic VTel axon bundles. To verify that many of the misguided VTel axons in EphBl $\mathrm{cKO}^{v g a t}$ mice originate from cortical, glutamatergic neurons, we used a virus labeling approach to label CaMKII $\alpha$-positive glutamatergic neurons in the somatosensory cortex (SSCtx), the origin of some of the misprojected VTel axons in EphB1 $1^{-/} ; E p h B 2^{-/-}$mice [2]. Indeed, in EphB1 $\mathrm{cKO}^{\text {gat }}$ mice, we observed misguided, CamKII-positive cortical glutamatergic axons in ectopic VTel axon bundles (Fig. 4A and B). We also labeled Vgat-positive cell axons in the dorsal striatum using a Cre-dependent virus approach in EphB1 $\mathrm{cKO}^{\text {Vgat }}$ mice. We detected co-fasciculation of Vgat-positive dorsal striatum axons and SSCtx glutamatergic cell axons within the VTel ectopic axon bundles and in the posterior branch of the anterior commissure (Fig. 4B). In contrast, we did not detect Vgat-positive SSCtx axons within the ectopic axon bundles of EphBl cKO ${ }^{\text {vgat }}$ mice (Suppl. Fig. 6).

\section{Loss of EphB1 in GABAergic D1 or D2 dopamine receptor-expressing populations does not phenocopy the axon guidance deficits observed in $E$ phB1 KO mice}

The vast majority of striatal GABAergic cells are SPNs that express D1 or D2 dopamine receptors [19]. To test whether EphB1 might play a critical role in D1- or D2-SPNs to produce the axon guidance defects, we first analyzed the effect of EphB1 $1^{-/-}$on D1- and D2-SPN projections in the Drd1a-tdTomato or Drd2-GFP reporter mice. However, we failed to detect tdTomato-positive (D1) or GFP-positive (D2) axons within the VTel axon bundles in EphB1/- mice (Suppl. Fig. 7A and $B$ ). Moreover, conditional EphB1 KO in either Drd1a-Cre or Drd2-Cre transgenic lines (EphB1 $\mathrm{cKO}^{\mathrm{D} 1}$ and $E p h B 1 \mathrm{cKO}^{\mathrm{D} 2}$ ) failed to produce the axon guidance deficits (Figs. $5 C$ and $D$ ), suggesting that the VTel axon guidance phenotype in $E p h B 1^{-/-}$mice is not caused by a key role in developing D1- or D2-SPNs.

A sub-population of somatostatin-positive (Sst) and parvalbumin-positive (PV) GABAergic neurons are known to project long-range ([18] and Fig. 6A). Indeed, we detected PVpositive axons within the misguided axon bundles in $E p h B 1^{\Delta \mathrm{Ex} 3 / \Delta \mathrm{Ex} 3} ; \operatorname{tdTomato}^{\mathrm{PV}}$ mice (Fig. 6B), suggesting that EphB1 might play a key role in PV neurons to produce the cortical glutamatergic axon guidance errors in the $E p h B 1 \mathrm{cKO}^{\mathrm{vgat}}$ mice. However, we observed no axon guidance defects 
in either EphB1 cKO ${ }^{\text {sst }}$ mice (Fig. $5 B$ ) or EphBl KO ${ }^{\mathrm{PV}}$ mice (data not shown). However, unlike Sst-Cre, which expressed in early embryonic development [20], Cre expression in the PV-Cre mice doesn't begin until postnatal day 8 [20], long after the embryonic period when EphB1-dependent axon guidance defects are first observed [2].

\section{Loss of EphB1 produces aberrant axon tracts along blood vessels in the ventral telencephalon}

Little is known about the interactions between developing brain vasculature and central nervous system axon guidance. In the $E p h B 1^{\Delta \mathrm{Ex} 3 / \Delta \mathrm{E} \times 3}$ mice, we noticed that the VTel ectoptic axon fascicles were typically located in a similar anatomical location and pattern as VTel vasculature (Fig. 7A) [21-23]. Interestingly, the ectopic axon bundles in EphB1 ${ }^{\Delta \mathrm{Ex} 3 / \Delta \mathrm{Ex} 3}$ mice were observed in close apposition to large CD31-positive blood vessels (adults; Fig. 7B) and elastin-positive arteries (P0; Fig. 7C), suggesting that EphB1 might promote repulsion of the misguided striatal and cortical axons from developing and mature brain vasculature. In addition, long-range GABAergic projections were observed in the ectopic axon bundles located beside the striatal blood vessels (Fig. 7D).

Vascular endothelial cells express many axon guidance molecules, including members of the Eph/ephrin family [24, 25], and they are required for proper vasculature development. Moreover, a subpopulation of endothelial cells also express Vgat and dlx [26, 27]. To determine if the $E p h B 1^{\Delta \mathrm{Ex} 3 / \Delta \mathrm{Ex} 3}$ mice VTel axon guidance defects are produced, at least in part, by Vgat/dlxexpressing endothelial cells, we generated vascular endothelial cell-specific EphB1 cKO ${ }^{\text {Tie2 }}$ mice using Tie2-Cre mice [28], where Cre expression in endothelial cells begins by $~ E 13$ [27]. However, while the Tie2-Cre mice showed specific brain vasculature recombination (Suppl. Fig. $8 A$ ), the EphB1 $\mathrm{cKO}^{\text {Tie2 }}$ mice displayed no VTel axon guidance or brain vasculature phenotypes (Suppl. Fig. 8B). These data suggest that EphB1 does not cause the cortical axon guidance deficits via a role in endothelial cells, but rather that GABAergic axons lacking EphB1 might fail to avoid developing VTel vasculature.

\section{DISCUSSION}

To identify the cell populations in which EphB1 is required to regulate cortical long-range axon guidance, we generated and validated a new floxed EphB1 mouse. This novel tool allowed us to show that, despite its expression in long-range glutamatergic cortical neurons, EphB1 functions in GABAergic cell populations, but surprisingly not striatal SPNs, to influence the proper cortical glutamatergic axon guidance in the developing striatum. We also detected GABAergic axons, including PV-positive cell axons, within the co-fasciculated ectopic axon bundles, suggesting the intriguing possibility that EphB1 is required for PV cell long-range axon guidance, and that cortical glutamatergic axons are misrouted as an indirect consequence. Moreover, the absence of EphB1 in GABAergic cells causes the misguided VTel axons to navigate along the 
developing striatal vasculature, possibly due to a failure of VTel axons to repel from ephrinexpressing vascular endothelial cells.

Based on the corticothalamic handshake hypothesis [13], and our previous findings in $E p h B 1^{-/-} ; E p h B 2^{-/-}$mice showing deficits in both cortical and thalamic axon guidance [2], we speculated that the cortical axon guidance errors were an indirect effect of a role for EphB1 and EphB2 in ascending thalamocortical axons in the developing VTel. In the current study, we focused on the VTel axon guidance phenotypes in the single EphB1-/ mouse, which were less

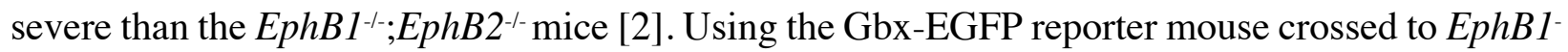
'- mice, we observed VTel axon guidance errors, but normal thalamocortical axon projections and no comingling of L1CAM+ ectopic cortical axons with the GFP-positive thalamic axons. Careful examination revealed that EphB1 is highly expressed in the epithalamus (future habenula), but not detectably in the developing thalamus. However, no habenular axon guidance defects were observed in the EphB1/- mice. These findings suggest that the VTel axon guidance defects in $E p h B 1^{-/-}$mice are not likely to be caused by defects in thalamocortical axon guidance. However, EphB2 is expressed in the thalamus [2], so future studies in compound mutant mice will be required to investigate how EphB1 and EphB2 cooperate to influence proper thalamocortical axon guidance.

Using viral-mediated axon tracing tools, we detected GABAergic axons intermingled with the misguided cortical axon bundles in the VTel and located along large blood vessels. Since EphB1 is not required within excitatory cortical neurons for the axon guidance phenotypes, but is necessary in Vgat and dlx1/2-expressing cells, our findings suggest that EphB1 functions in a subset of GABAergic neurons to control proper long-range GABAergic axon guidance and avoidance of the developing VTel vasculature. Moreover, the cortical glutamatergic axon guidance defect is likely caused by co-fasciculation of the descending cortical glutamatergic neuron axons along the misrouted GABAergic fibers. As such, this suggests that a subset of long-range cortical axons might normally fasciculate along a subpopulation of long-range GABAergic axons to reach their proper target. Indeed, a subpopulation of axons from the somatosensory and motor cortex does project to the globus pallidus [29], which is the predominant target of striatal SPNs. Moreover, the EphB1 ${ }^{-/}$mice display a reduction in corticospinal tract axons [4], suggesting that the misguided axons also normally project caudally.

While D1- and D2-SPNs are the predominant, long-range projecting GABAergic cell type in the striatum, conditional loss of EphB1 in D1 or D2 dopamine receptor-expressing cells failed to produce axon guidance defects, and no D1 or D2-positive axons were clearly observed in the ectopic bundles. However, a very small immature population of SPNs [19] might be the population giving rise to the misrouted striatal axons labeled by the viral approach. Sst-positive interneurons in the striatum can project over long distances within the striatum [30], but conditional EphBI $\mathrm{cKO}^{\text {sst }}$ failed to produce the EphB1 $1^{-/-}$phenotypes. In normally developing striatum, the PVexpressing GABAergic interneurons project at short-ranges [30], but it remains possible that loss of EphB1 allows striatal PV-positive cells to misproject. In addition, a sub-population of PVpositive neurons $(\sim 17 \%)$ in the globus pallidus projects to the striatum [31], and loss of EphB1 in 
this population could misroute their axons within the striatum. Unfortunately, PV-Cre expression doesn't begin until long-after the guidance defects occur [20], so while PV is useful cell-type marker in mature mice, it's not useful for early embryonic manipulation of EphB1. Interestingly, the Eph/ephrin system is required for the proper migration of GABAergic neurons generated in the ganglionic eminences and preoptic area [6, 32-36]. As such, it's possible in EphB $1^{-/-}$mice that GABAergic cortical neurons abnormally migrate and stay into the developing striatum and produce GABAergic axon projections that are not normally present in WT mice. Currently, there are no Cre transgenic mice available that specifically express only in migrating GABAergic neurons going to the cortex to test this possibility. Finally, since conditional deletion of EphBl in D1-SPNs, D2-SPNs, or Sst interneurons alone does not produce axon guidance phenotypes, future studies will be needed to identify the specific GABAergic cell subtypes responsible for the EphB1 $\mathrm{KO}^{\text {vat }}$ axon guidance phenotypes (e.g., precursors of PV cells, a non-neuronal and Vgat/dlxpositive cell population).

We found that a subset of striatal GABAergic and cortical glutamatergic axons in $E p h B 1^{\Delta \mathrm{Ex} 3 / \Delta \mathrm{Ex} 3}$ and $E p h B 1 \mathrm{cKO}^{\mathrm{Vgat}}$ are in close apposition to large blood vessels in the VTel, but conditional loss of EphB1 in Tie2-expresssing vascular endothelial cells did not produce the noted axon guidance deficits. There remains a possibility that EphB1 could be expressed in oligodendrocyte precursor cells (OPCs), mural cells, or pericytes [37-43] to influence the apposition of the misguided axons along the developing VTel vasculature, but future studies will be needed to rule out a possible role in those cell types. The developing vasculature and navigating axons express many of the same guidance molecules, including ephrins and Ephs [24, 44], suggesting that both systems can influence each other. However, the interplay between axon navigation and the developing vasculature only begins to be examined [45-48]. Several studies showed that some peripheral nerves (e.g. autonomic sympathetic axons) navigate along the vasculature via attractive cues expressed on, or secreted by, blood vessels [49]. Conversely, certain sensory nerves can provide a template to guide arterial patterning [44]. Here, we add to this literature by showing that blood vessels also appear to influence striatal and cortical axon guidance. Except in the external capsule, cortical and striatal axons are generally not found in close apposition to the major blood vessels in the VTel, suggesting that EphB1 likely mediates the repulsion of these VTel axons from developing blood vessels. The arteriole endothelium expresses ephrinB2 [25, 50, 51], which could promote EphB1-dependent repulsion of navigating axons in the VTel. Unfortunately, loss of ephrinB2 from endothelial cells leads to early embryonic lethality (by E11.5) due to angiogenic defects [25], precluding our ability to examine whether loss of vascular ephrinB2 produces the VTel axon guidance phenotypes seen in the EphB1 $1^{- \text {- }}$ mice.

Together, our findings reveal that EphB1 controls proper long-range cortical axon guidance through a cell non-autonomous role in GABAergic cells. EphB1 is also required to prevent cortical and striatal axons from extending along developing ventral telencephalic vasculature. 
Acknowledgments: The authors would like to thank Dr. Mark Henkemeyer for sharing the EphB1-lacZ knock-in mice, and Ben Zirlin for help managing the mouse colony. These studies were supported by NIH grants MH111464, a SFARI research grant \#240332 from the Simons Foundation, and the MUSC Proteogenomics Facility (NIH GM103499).

Author contributions: GC designed, produced, and validated at the genomic level the floxed EphB1 exon 3 targeting vector. AA performed and analyzed all of the other experiments described in this paper. AA and CWC designed experiments and wrote the paper.

\section{LEGENDS}

Figure 1: Axon guidance defects in EphB1 KO mice on a C57Bl6/J background. A and B. L1CAM staining on coronal sections at three different rostro-caudal levels at P0 in control mice (A), and in EphB $1^{-/}$mice (B), with abnormal axon bundles in the dorsal striatum joining the external capsule and posterior branch of the anterior commissure, and terminating in the ventral part of the brain, as well as abnormal axon bundles in the internal capsule. C. Magnified images corresponding to the white squares in B. ctx: cortex; str: striatum; cc: corpus callosum; ec: external capsule; ic: internal capsule; pac: posterior branch of the anterior commissure. V: ventral; M: medial.

Figure 2: Generation and validation of floxed EphB1 mice. A. Scheme representing floxed EphB1 mice generation. The inserted sequence included a first lox $\mathrm{P}$ site, a first FRT site, a GFP and neomycin selection cassette (Neo), a second FRT site, the EphB1 exon 3, and a second loxP site. Mice were crossed to Flp recombinase germline expression mice to remove the FRT flanked knock-in cassettes to generate $E p h B 1^{\text {lox/lox }}$ mice. Breeding $E p h B 1^{\text {lox/lox }}$ mice to Cre lines induces conditional deletion of EphBI exon 3, premature stop codon, ultimately producing EphBI conditional knockout mice. B. Generation of a novel global EphB1 knockout mouse. EphB1 1ox/lox mice were crossed to Prm-Cre mice to generate germline transmission of the EphB1 loss-offunction allele $\left(E p h B 1^{\Delta \mathrm{Ex} 3 / \Delta \mathrm{Ex} 3}\right)$. RT-PCR showing efficient recombination of $E p h B 1$ exon 3 in $E p h B 1^{\Delta \mathrm{Ex} 3 / \Delta \mathrm{Ex} 3}$ mice compared to control mice (excised exon 3 band: 153bp; control band: $880 \mathrm{bp}$ ). GAPDH was used as a control. C. L1CAM staining on coronal sections at three different rostrocaudal levels at $\mathrm{P} 0$ on $E p h B 1^{\Delta \mathrm{E} \times 3 / \Delta \mathrm{Ex} 3}$ mice, showing the same axon guidance defects (arrows) as in global EphB1 $1^{-/-}$mice. V: ventral; M: medial.

Figure 3: Axon guidance defects after EphB1 deletion from GABAergic cells. A-D. L1CAM staining on coronal sections at two different rostro-caudal levels at P0 in controls (A and C), in $E p h B 1 \mathrm{cKO}^{\mathrm{Emx}}(\mathrm{B})$, and in $E p h B 1 \mathrm{cKO}^{\text {vgat }}(\mathrm{D})$. EphB1 deletion from GABAergic cells, but not glutamatergic cells, phenocopies the axon guidance defects (arrows) found in the global EphB1/mice. E and F. L1CAM and tdTomato co-staining on coronal sections at P0 in EphB1 
$\mathrm{cKO}^{\text {Vgat }}$;dTomato ${ }^{\text {gat }}$ mice (Vgat-Cre x EphB $1^{\text {lox/lox }} \times$ Ai14), showing that the misguided axon bundles include long-range GABAergic projections (arrows). V: ventral; M: medial.

Figure 4: Ectopic cortical glutamatergic projections intermingle with misguided striatal long-range GABAergic projections in EphB1 cKO $^{\text {gat }}$ mice. A and B. Ds-Red and GFP costaining on coronal sections in adulthood in control mice (A) and EphBl $\mathrm{cKO}^{\text {vgat }}$ mice (B), following Cre-dependent (DIO) mCherry AAV virus injections in the dorsal striatum and CaMKII GFP AAV virus injections in the somatosensory cortex. V: ventral; M: medial.

Figure 5: No axon guidance defects after $E$ phB1 deletion from D1- or D2-SPNs. A-D. L1CAM staining on coronal sections at two different rostro-caudal levels at P0 in EphB1 $c K O^{\mathrm{dl} x 1 / 2}$ (A), in EphB1 cKO $O^{\text {st }}(\mathrm{B})$, in EphB1 $\mathrm{cKO}^{\mathrm{D} 1}(\mathrm{C})$, and in EphB1 $\mathrm{cKO}^{\mathrm{D} 2}(\mathrm{D})$. V: ventral; M: medial.

Figure 6: Misguided axons in EphB1-lacking mice include long-range projections from parvalbumin-positive neurons. A. Ds-Red staining on coronal sections at two different rostrocaudal levels in adult tdTomato ${ }^{\mathrm{PV}}$ mice (PV-Cre $\mathrm{x}$ Ai14), showing long-range projections from parvalbumin-positive neurons, including in the dorsal striatum. B. Myelin and Ds-Red co-staining on different coronal sections in adult $E p h B 1^{\Delta \mathrm{Ex} 3 / \Delta \mathrm{Ex} 3} ;$ tdTomato $^{\mathrm{PV}}$, showing that the misguided axon bundles include long-range projections from parvalbumin-positive neurons.

Figure 7: Misguided axons juxtapose with major blood vessels in EphB1-lacking mice. A. Scheme representing major arteries of the mouse cerebral vasculature adapted from Dorr et al [21]. B. CD31 (endothelial cells marker) and myelin co-staining on different coronal sections in adult $E p h B 1^{\Delta \mathrm{E} \times 3 / \Delta \mathrm{Ex} 3}$ mice. C. Elastin (arteries marker) and L1CAM co-staining on different coronal sections in $\mathrm{P} 0 \mathrm{EphB} 1^{\Delta \mathrm{E} \times 3 / \Delta \mathrm{Ex} 3}$ pups. D. CD31, tdTomato, and myelin co-staining on adult EphB1 cKO $^{\text {vgat;tdTomato }}{ }^{\text {vgat }}$ mice (Vgat-Cre x EphB1 $1^{\text {lox/lox }}$ x Ai14). V: ventral; M: medial.

Supplemental Figure 1: Generation of floxed EphB1 mice. All details are in the materials and methods section.

\section{Supplemental Figure 2: PCR mix and PCR program to genotype floxed EphB1 mice.}

Supplemental Figure 3: No misguided thalamic projections in EphB1 KO mice. A and B. GFP staining of thalamic nuclei and projections on coronal sections at two different rostro-caudal levels at P0 in GFPGbx control (A) and in GFPGbx; EphB1 KO pups (B). C and C'. L1CAM and GFP co-staining on coronal sections at two different rostro-caudal levels in P0 GFPGbx; EphB1 KO pups. D and E. Vglut2 and DAPI co-staining on tangential sections of flattened barrel cortex in adult control (D) and EphB1 KO mice (E). V: ventral; M: medial. 
Supplemental Figure 4: EphB1 expression in the habenula. A. GFP and Xgal co-staining on coronal sections at E14.5 in GFPGbx;EphB1-LacZ embryos. B. Brn3a (marker of developing habenula) and Xgal co-staining on coronal sections of the habenula at E14.5 in EphB1-LacZ embryos. C. Xgal staining on coronal sections of the habenula in adult EphB1-LacZ mice. D. L1CAM staining on coronal sections of habenular axon tracts at P0 in control (upper panel in D) and $E p h B 1^{-/-}$mice (lower panel in D).

Supplemental Figure 5: EphB1 deletion validation in $E p h B 1 \mathrm{cKO}^{\mathrm{Emx}}$ and in $E p h B 1 \mathrm{cKO}^{\text {vgat }}$ mice. A and B. RT-PCR showing specific recombination of EphB1 exon 3 in EphB1 $\mathrm{cKO}^{\mathrm{Emx}}$ mice (excised exon 3: no band; control band: 545bp) (A) and in EphB1 $\mathrm{cKO}^{\text {gat }}$ mice (excised exon 3 band: $153 \mathrm{bp}$; control band: $880 \mathrm{bp}$ ) (B) compared to control mice. The two sets of primers for detection are described in the materials and methods section. GAPDH was used as a control. SSCtx: somatosensory cortex; Hippo: hippocampus; Str: striatum. C. tdTomato and Vgat costaining using fluorescent in situ hybridization (RNAscope) on coronal sections of the dorsal striatum in tdTomato $^{\text {Vgat }}$ mice, showing perfect colocalization between tdTomato and endogenous Vgat. D. EphB1 and Vgat co-staining using RNAscope on coronal sections of the dorsal striatum in tdTomato ${ }^{\text {Vgat }}$ control mice (upper panel in D) and in tdTomato ${ }^{\text {Vgat }}$; $E p h B 1 \mathrm{cKO}^{\text {vgat }}$ mice, showing loss of EphB1 expression in Vgat-positive cells after EphB1 deletion.

Supplemental Figure 6: No misguided cortical long-range GABAergic projections in EphB1 cKO $^{\text {vgat }}$ mice. Myelin and Ds-Red co-staining on coronal sections of adult EphBl $\mathrm{cKO}^{\text {vgat }}$ mice, following Cre-dependent (DIO) mCherry AAV virus injections in the somatosensory cortex.

Supplemental Figure 7: No clear misguided axons from D1- and D2-SPNs in EphB1 ${ }^{\Delta \mathrm{Ex} 3 / \Delta \mathrm{Ex} 3}$ mice. A. Myelin and Ds-Red co-staining on coronal sections of adult tdTomato ${ }^{\mathrm{D} 1} ; E p h B 1^{\triangle \mathrm{E} \times 3 / \Delta \mathrm{Ex} 3}$ mice. B. L1CAM and GFP co-staining on coronal sections of $\mathrm{GFP}^{\mathrm{D} 2} ; E p h B 1^{\triangle \mathrm{E} \times 3 / \Delta \mathrm{Ex} 3}$ pups at P0. V: ventral; M: medial.

Supplemental Figure 8: No axon guidance defects after EphB1 deletion from endothelial cells. A. Ds-Red staining on coronal sections at two different rostro-caudal levels in P0 tdTomato $^{\text {Tie2 }}$ pups (Tie2-Cre x Ai14). B. L1CAM staining on coronal sections at two different rostro-caudal levels in $\mathrm{PO}$ EphB1 $\mathrm{cKO}^{\mathrm{Tie} 2}$ pups.

\section{REFERENCES}

1. Kania, A. and R. Klein, Mechanisms of ephrin-Eph signalling in development, physiology and disease. Nat Rev Mol Cell Biol, 2016. 17(4): p. 240-56.

2. Robichaux, M.A., et al., EphB receptor forward signaling regulates area-specific reciprocal thalamic and cortical axon pathfinding. Proc Natl Acad Sci U S A, 2014. 111(6): p. 2188-93. 
3. Robichaux, M.A., et al., EphB1 and EphB2 intracellular domains regulate the formation of the corpus callosum and anterior commissure. Dev Neurobiol, 2016. 76(4): p. 405-20.

4. Lodato, S., et al., Gene co-regulation by Fezf2 selects neurotransmitter identity and connectivity of corticospinal neurons. Nat Neurosci, 2014. 17(8): p. 1046-54.

5. Grant, E., A. Hoerder-Suabedissen, and Z. Molnar, Development of the corticothalamic projections. Front Neurosci, 2012. 6: p. 53.

6. $\quad$ Rudolph, J., et al., A dual role of EphB1/ephrin-B3 reverse signaling on migrating striatal and cortical neurons originating in the preoptic area: should I stay or go away? Front Cell Neurosci, 2014. 8: p. 185.

7. Williams, S.E., et al., Ephrin-B2 and EphB1 mediate retinal axon divergence at the optic chiasm. Neuron, 2003. 39(6): p. 919-35.

8. Chenaux, G. and M. Henkemeyer, Forward signaling by EphB1/EphB2 interacting with ephrin-B ligands at the optic chiasm is required to form the ipsilateral projection. Eur $\mathrm{J}$ Neurosci, 2011. 34(10): p. 1620-33.

9. Liu, P., N.A. Jenkins, and N.G. Copeland, A highly efficient recombineering-based method for generating conditional knockout mutations. Genome Res, 2003. 13(3): p. 476-84.

10. Adams, D.J., et al., A genome-wide, end-sequenced 129Sv BAC library resource for targeting vector construction. Genomics, 2005. 86(6): p. 753-8.

11. Bochkov, Y.A. and A.C. Palmenberg, Translational efficiency of EMCV IRES in bicistronic vectors is dependent upon IRES sequence and gene location. Biotechniques, 2006. 41(3): p. 283-4, 286, 288 passim.

12. Utton, M.A., et al., The slow axonal transport of the microtubule-associated protein tau and the transport rates of different isoforms and mutants in cultured neurons. J Neurosci, 2002. 22(15): p. 6394-400.

13. Molnar, Z., et al., Mechanisms controlling the guidance of thalamocortical axons through the embryonic forebrain. Eur J Neurosci, 2012. 35(10): p. 1573-85.

14. Quina, L.A., et al., Brn3a and Nurr1 mediate a gene regulatory pathway for habenula development. J Neurosci, 2009. 29(45): p. 14309-22.

15. Liang, H., S. Hippenmeyer, and H.T. Ghashghaei, A Nestin-cre transgenic mouse is insufficient for recombination in early embryonic neural progenitors. Biol Open, 2012. 1(12): p. 1200-3.

16. Vong, L., et al., Leptin action on GABAergic neurons prevents obesity and reduces inhibitory tone to POMC neurons. Neuron, 2011. 71(1): p. 142-54.

17. Potter, G.B., et al., Generation of Cre-transgenic mice using Dlx1/Dlx2 enhancers and their characterization in GABAergic interneurons. Mol Cell Neurosci, 2009. 40(2): p. 16786.

18. Melzer, S. and H. Monyer, Diversity and function of corticopetal and corticofugal GABAergic projection neurons. Nat Rev Neurosci, 2020. 21(9): p. 499-515.

19. Anderson, A.G., et al., Single-Cell Analysis of Foxp1-Driven Mechanisms Essential for Striatal Development. Cell Rep, 2020. 30(9): p. 3051-3066 e7.

20. Taniguchi, H., et al., A resource of Cre driver lines for genetic targeting of GABAergic neurons in cerebral cortex. Neuron, 2011. 71(6): p. 995-1013.

21. Dorr, A., J.G. Sled, and N. Kabani, Three-dimensional cerebral vasculature of the CBA mouse brain: a magnetic resonance imaging and micro computed tomography study. Neuroimage, 2007. 35(4): p. 1409-23. 
22. Xiong, B., et al., Precise Cerebral Vascular Atlas in Stereotaxic Coordinates of Whole Mouse Brain. Front Neuroanat, 2017. 11: p. 128.

23. Kirst, C., et al., Mapping the Fine-Scale Organization and Plasticity of the Brain Vasculature. Cell, 2020. 180(4): p. 780-795 e25.

24. Walchli, T., et al., Wiring the Vascular Network with Neural Cues: A CNS Perspective. Neuron, 2015. 87(2): p. 271-96.

25. Adams, R.H., et al., Roles of ephrinB ligands and EphB receptors in cardiovascular development: demarcation of arterial/venous domains, vascular morphogenesis, and sprouting angiogenesis. Genes Dev, 1999. 13(3): p. 295-306.

26. Baruah, J. and A. Vasudevan, The Vessels Shaping Mental Health or Illness. Open Neurol J, 2019. 13: p. 1-9.

27. Li, S., et al., Endothelial cell-derived GABA signaling modulates neuronal migration and postnatal behavior. Cell Res, 2018. 28(2): p. 221-248.

28. Kisanuki, Y.Y., et al., Tie2-Cre transgenic mice: a new model for endothelial cell-lineage analysis in vivo. Dev Biol, 2001. 230(2): p. 230-42.

29. Karube, F., et al., Motor cortex can directly drive the globus pallidus neurons in a projection neuron type-dependent manner in the rat. Elife, 2019. 8.

30. Straub, C., et al., Principles of Synaptic Organization of GABAergic Interneurons in the Striatum. Neuron, 2016. 92(1): p. 84-92.

31. Saunders, A., K.W. Huang, and B.L. Sabatini, Globus Pallidus Externus Neurons Expressing parvalbumin Interconnect the Subthalamic Nucleus and Striatal Interneurons. PLoS One, 2016. 11(2): p. e0149798.

32. Zimmer, G., et al., Ephrin-A5 acts as a repulsive cue for migrating cortical interneurons. Eur J Neurosci, 2008. 28(1): p. 62-73.

33. Steinecke, A., et al., EphA/ephrin A reverse signaling promotes the migration of cortical interneurons from the medial ganglionic eminence. Development, 2014. 141(2): p. 460-71.

34. Rudolph, J., et al., Ephrins guide migrating cortical interneurons in the basal telencephalon. Cell Adh Migr, 2010. 4(3): p. 400-8.

35. Zimmer, G., et al., Bidirectional ephrinB3/EphA4 signaling mediates the segregation of medial ganglionic eminence- and preoptic area-derived interneurons in the deep and superficial migratory stream. J Neurosci, 2011. 31(50): p. 18364-80.

36. Talebian, A., et al., Autonomous and non-autonomous roles for ephrin-B in interneuron migration. Dev Biol, 2017. 431(2): p. 179-193.

37. Tsai, H.H., et al., Oligodendrocyte precursors migrate along vasculature in the developing nervous system. Science, 2016. 351(6271): p. 379-84.

38. Jung, B., et al., Visualization of vascular mural cells in developing brain using genetically labeled transgenic reporter mice. J Cereb Blood Flow Metab, 2018. 38(3): p. 456-468.

39. Karram, K., N. Chatterjee, and J. Trotter, NG2-expressing cells in the nervous system: role of the proteoglycan in migration and glial-neuron interaction. J Anat, 2005. 207(6): p. 735-44.

40. Petryniak, M.A., et al., Dlx1 and Dlx2 control neuronal versus oligodendroglial cell fate acquisition in the developing forebrain. Neuron, 2007. 55(3): p. 417-33.

41. Tran, M.N., et al., Single-nucleus transcriptome analysis reveals cell-type-specific molecular signatures across reward circuitry in the human brain. Neuron, 2021. 109(19): p. 3088-3103 e5. 
42. Linneberg, C., M. Harboe, and L.S. Laursen, Axo-Glia Interaction Preceding CNS Myelination Is Regulated by Bidirectional Eph-Ephrin Signaling. ASN Neuro, 2015. 7(5).

43. Saunders, A., et al., Molecular Diversity and Specializations among the Cells of the Adult Mouse Brain. Cell, 2018. 174(4): p. 1015-1030 e16.

44. Adams, R.H. and A. Eichmann, Axon guidance molecules in vascular patterning. Cold Spring Harb Perspect Biol, 2010. 2(5): p. a001875.

45. Carmeliet, P. and M. Tessier-Lavigne, Common mechanisms of nerve and blood vessel wiring. Nature, 2005. 436(7048): p. 193-200.

46. Mukouyama, Y.S., et al., Sensory nerves determine the pattern of arterial differentiation and blood vessel branching in the skin. Cell, 2002. 109(6): p. 693-705.

47. Mondo, E., et al., A Developmental Analysis of Juxtavascular Microglia Dynamics and Interactions with the Vasculature. J Neurosci, 2020. 40(34): p. 6503-6521.

48. Andreone, B.J., B. Lacoste, and C. Gu, Neuronal and vascular interactions. Annu Rev Neurosci, 2015. 38: p. 25-46.

49. Mukouyama, Y.S., Vessel-dependent recruitment of sympathetic axons: looking for innervation in all the right places. J Clin Invest, 2014. 124(7): p. 2855-7.

50. Wang, H.U., Z.F. Chen, and D.J. Anderson, Molecular distinction and angiogenic interaction between embryonic arteries and veins revealed by ephrin-B2 and its receptor Eph-B4. Cell, 1998. 93(5): p. 741-53.

51. Gerety, S.S., et al., Symmetrical mutant phenotypes of the receptor EphB4 and its specific transmembrane ligand ephrin-B2 in cardiovascular development. Mol Cell, 1999. 4(3): p. 403-14. 
bioRxiv preprint doi: https://doi.org/10.1101/2022.02.28.482352; this version posted March 1, 2022. The copyright holder for this preprint (which was not certified by peer review) is the author/funder, who has granted bioRxiv a license to display the preprint in perpetuity. It is made available under aCC-BY-NC-ND 4.0 International license.

\section{Figure 1}

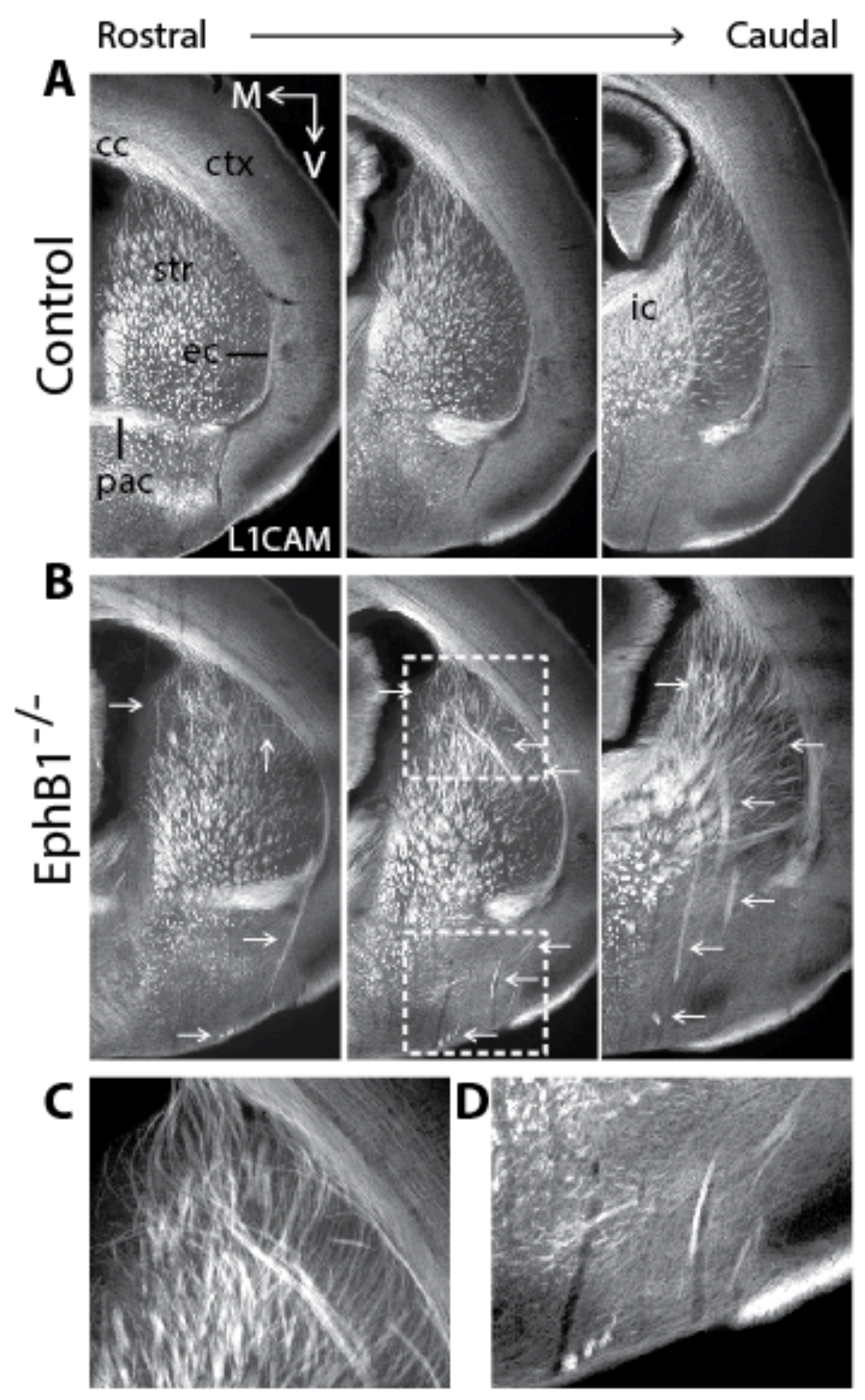




\section{Figure 2}

\section{A Generation of floxed EphB1 mice}

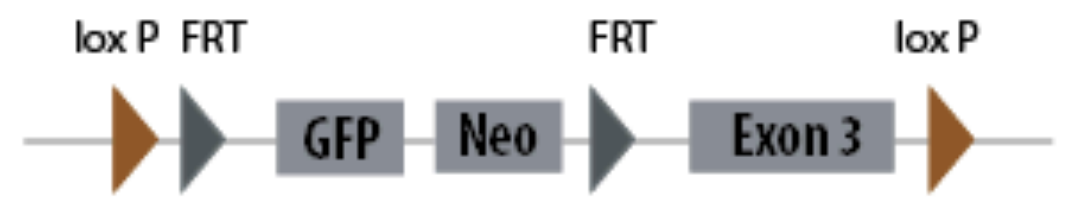

Flp recombination $\downarrow$

Cre recombination $\downarrow$

\section{Exon 3}

B

\section{Generation of EphB1 $\Delta \mathrm{Ex} 3 / \Delta \mathrm{Ex} 3$}

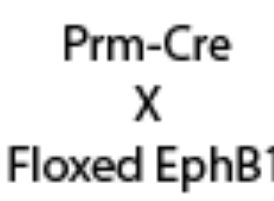

C

EphB1 $\Delta \mathrm{Ex3} / \Delta \mathrm{Ex3}$
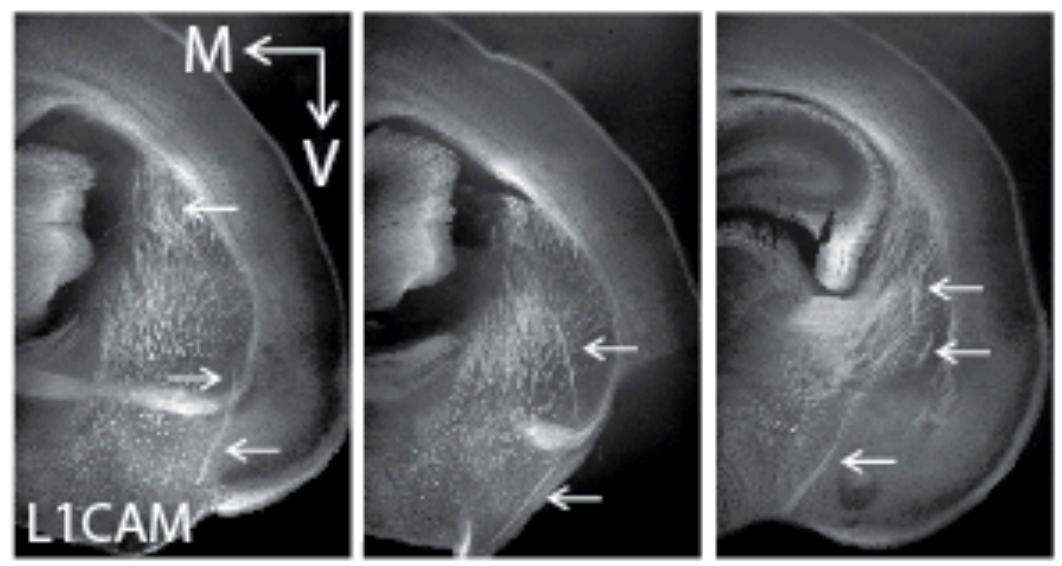


\section{Figure 3}

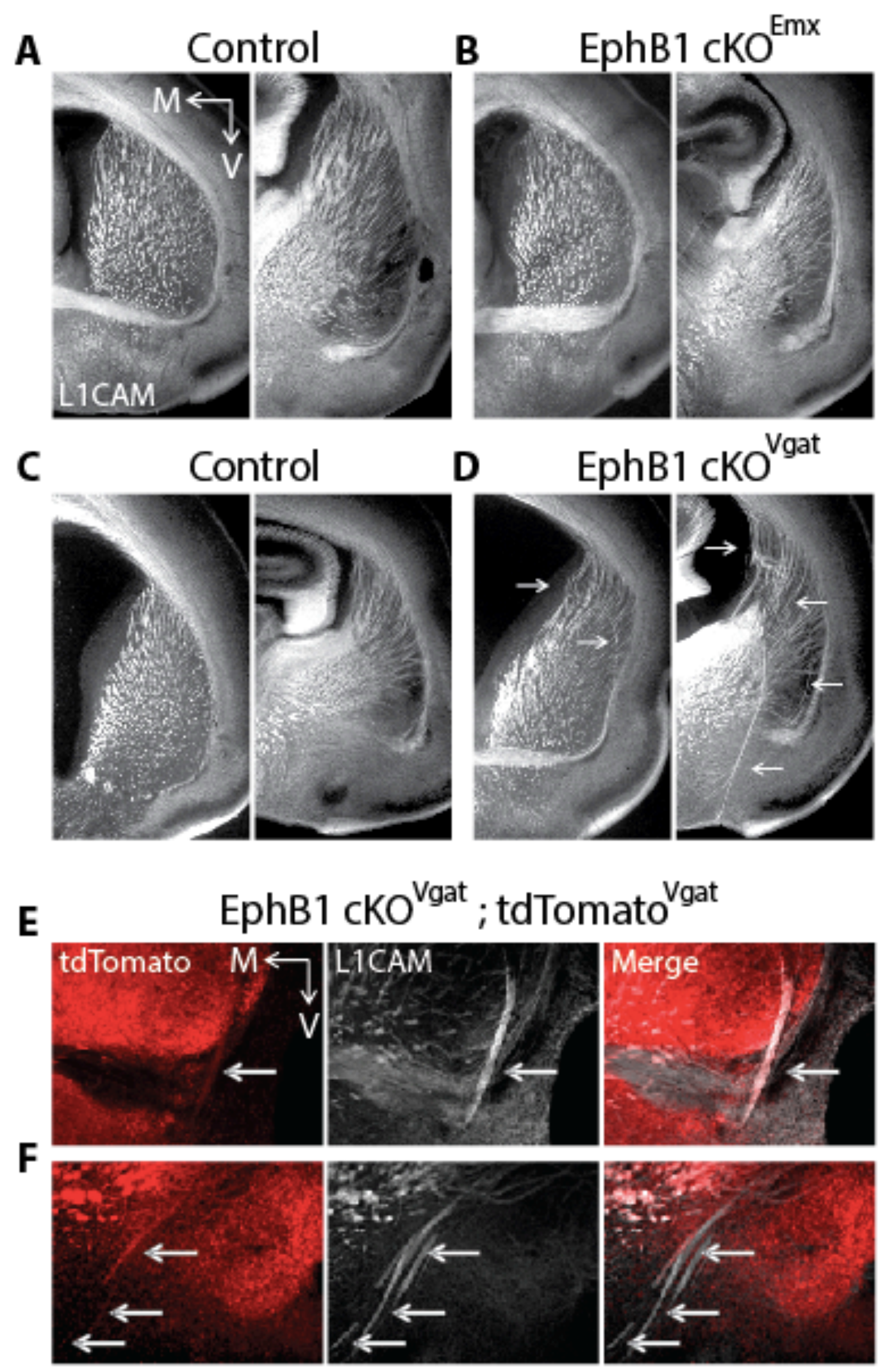




\section{Figure 4}

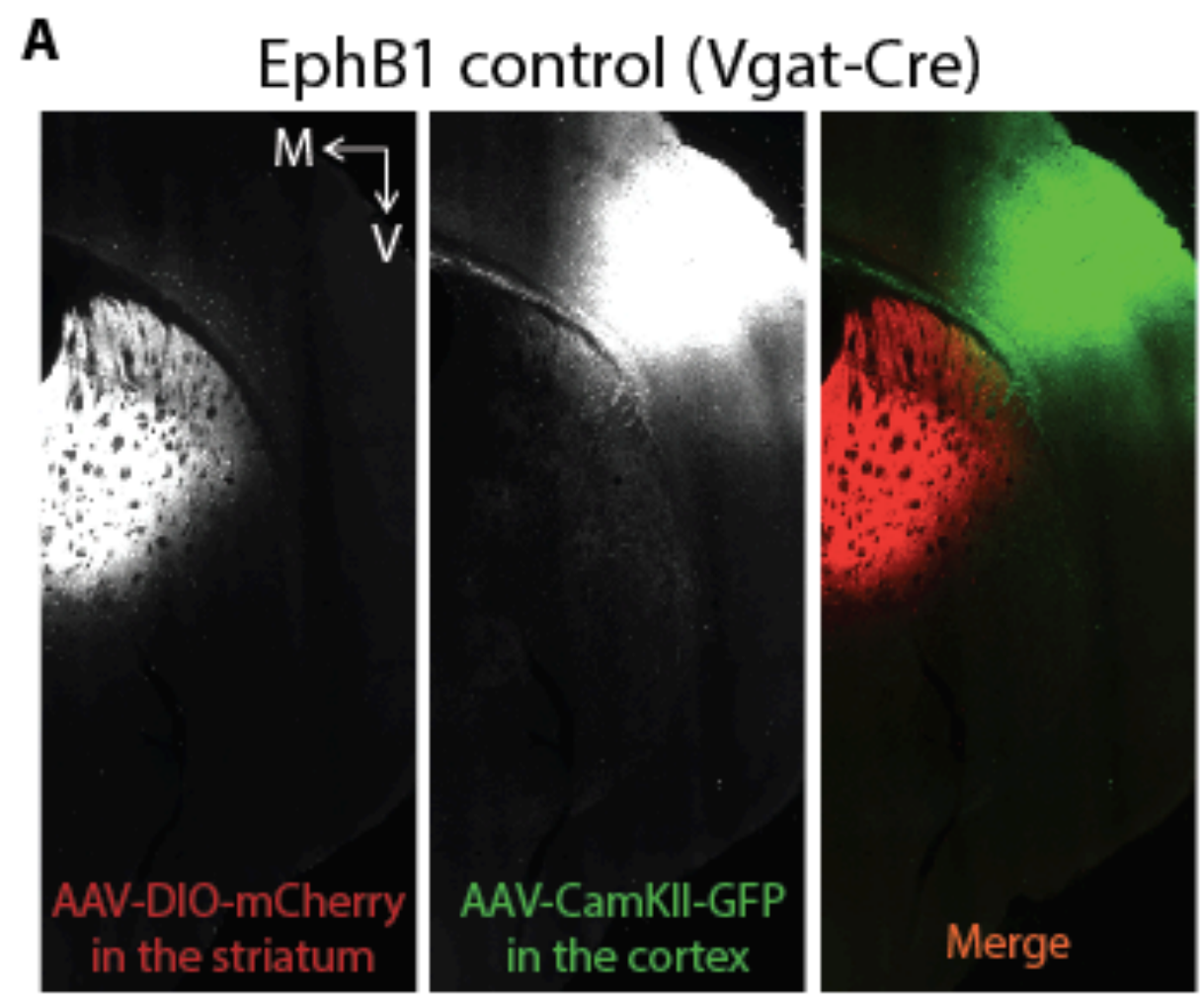

${ }^{B}$ EphB1 cKO ${ }^{\text {Vaat }}\left(\right.$ Vgat-Cre x EphB1 $\left.1^{\text {loxlox }}\right)$
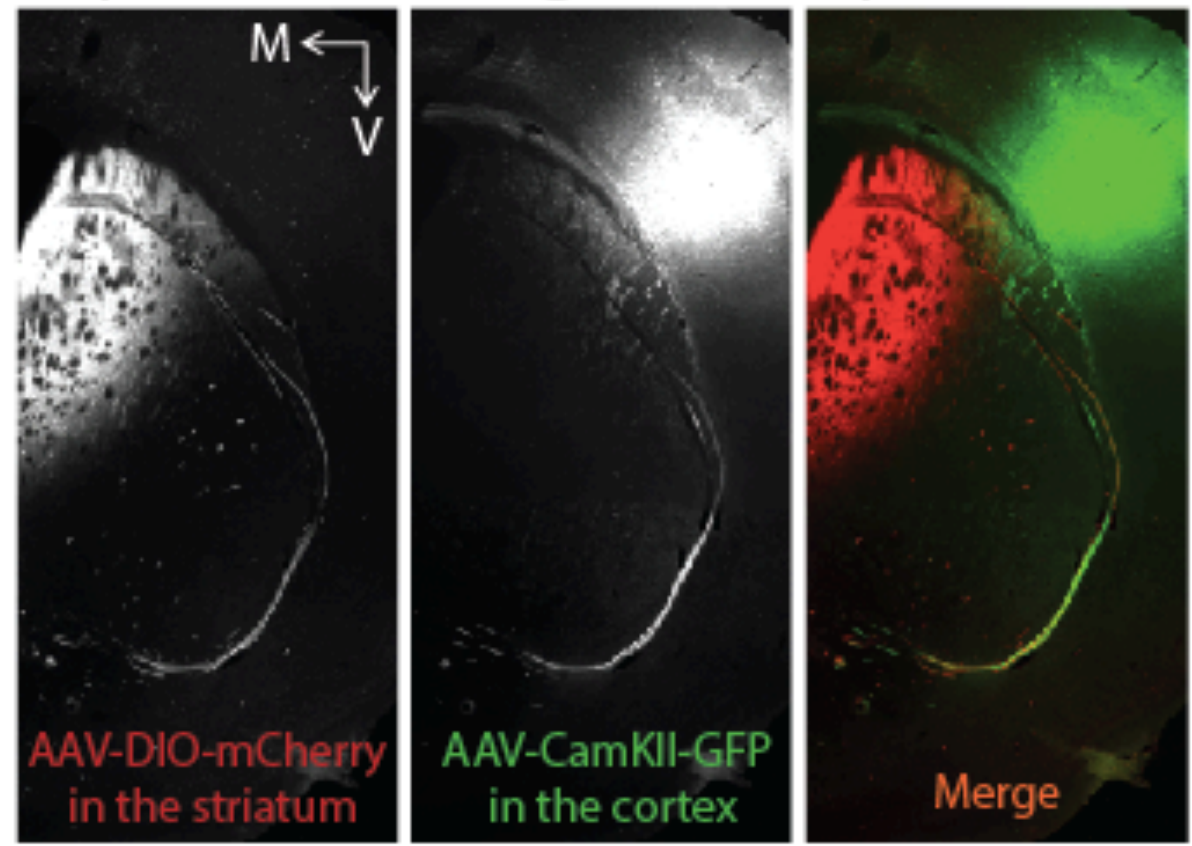
bioRxiv preprint doi: https://doi.org/10.1101/2022.02.28.482352; this version posted March 1, 2022. The copyright holder for this preprint (which was not certified by peer review) is the author/funder, who has granted bioRxiv a license to display the preprint in perpetuity. It is made available under aCC-BY-NC-ND 4.0 International license.

\section{Figure 5}

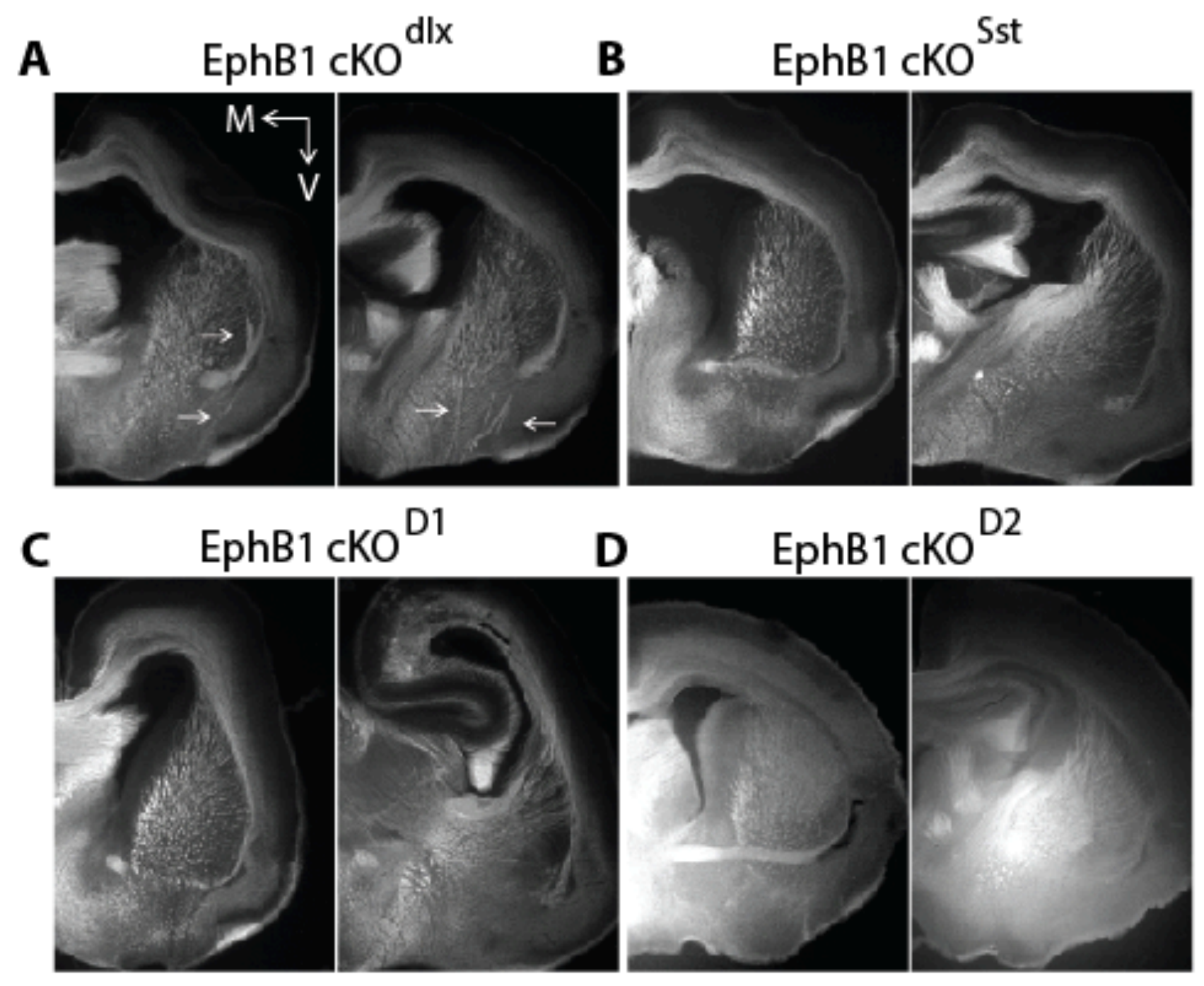


bioRxiv preprint doi: https://doi.org/10.1101/2022.02.28.482352; this version posted March 1, 2022. The copyright holder for this preprint (which was not certified by peer review) is the author/funder, who has granted bioRxiv a license to display the preprint in perpetuity. It is made available under aCC-BY-NC-ND 4.0 International license.

\section{Figure 6}

A

tdTomato $^{\text {PV }}$ (PV-Cre x Ai14)
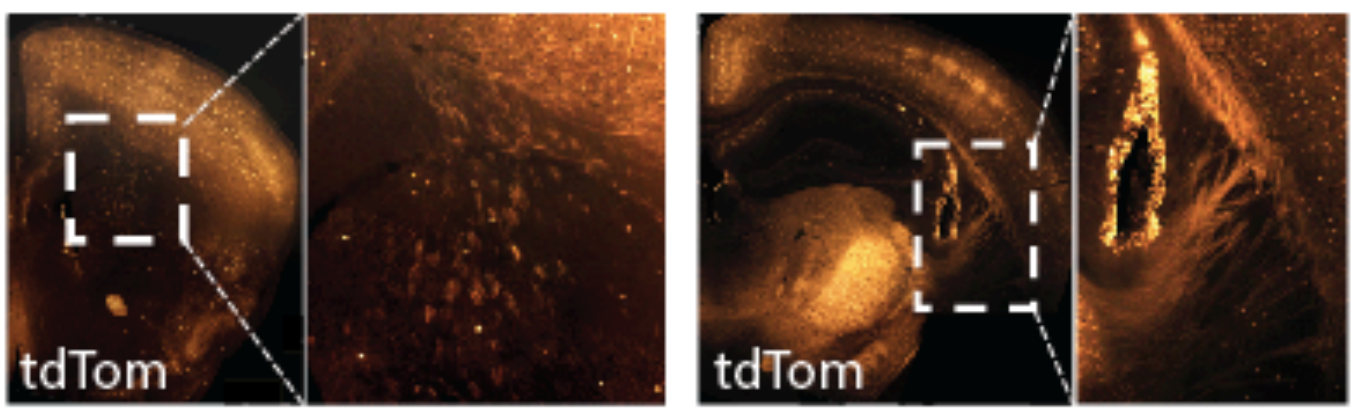

B

$\mathrm{EphB} 1^{\Delta \mathrm{Ex} 3 / \Delta \mathrm{Ex} 3} ;$ tdTomato $^{\mathrm{PV}}$

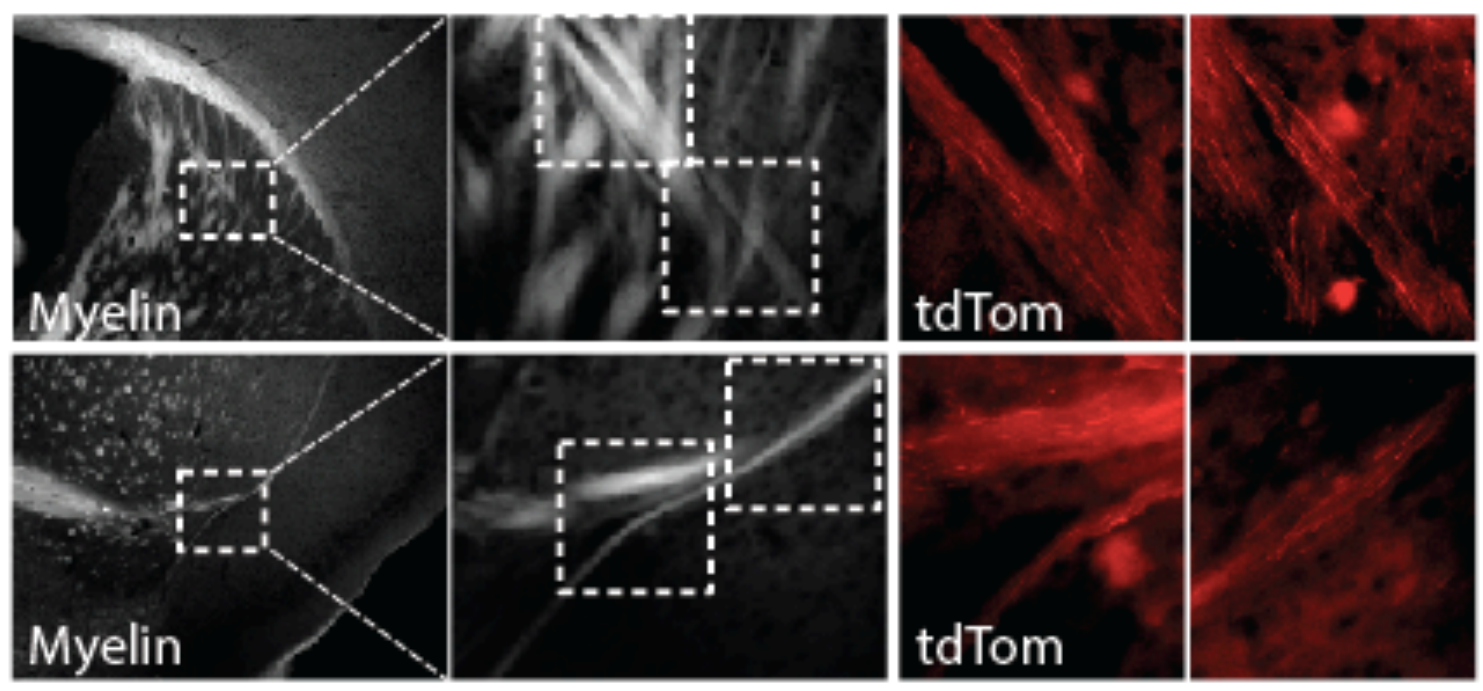




\section{Figure 7}

A Major arteries of the mouse cerebral vasculature

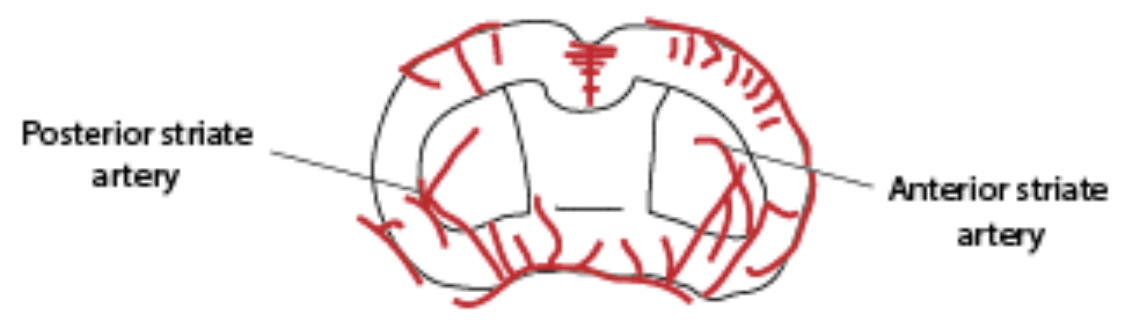

B
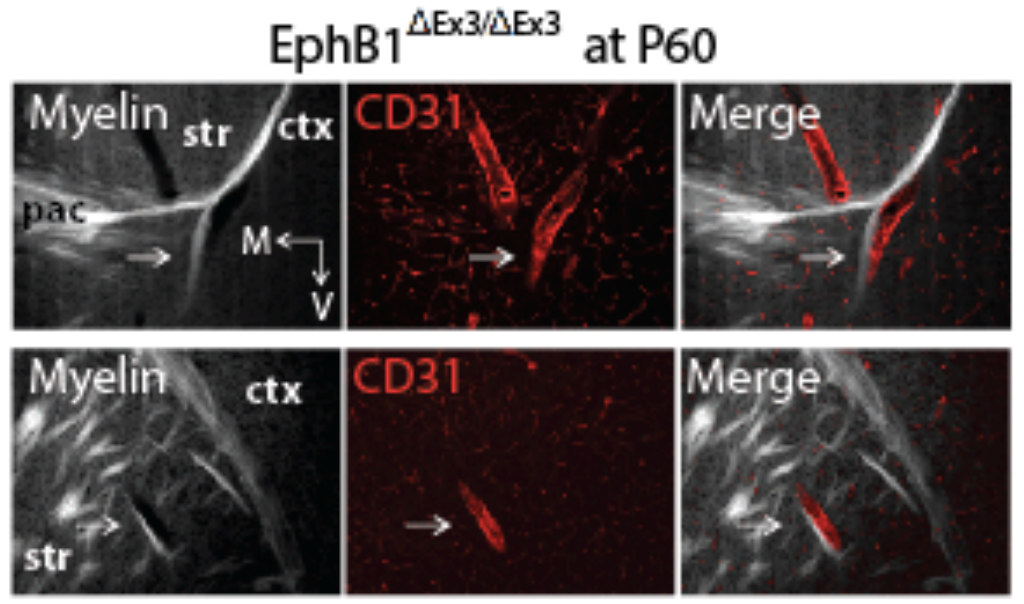

C

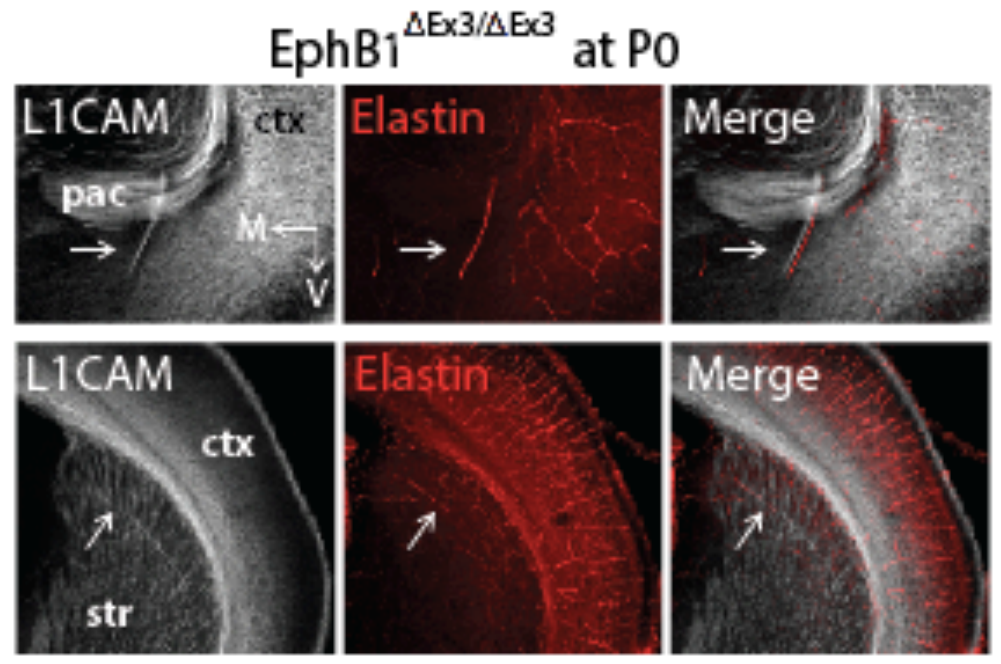

D

EphB1 $\mathrm{cKO}^{\text {Vgat }}$; tdTomato ${ }^{\text {Vgat }}$ at P60

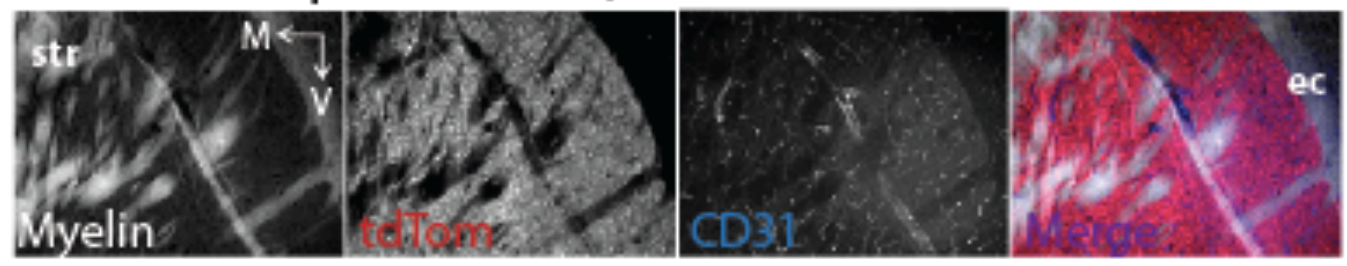

